\title{
NARRATIVAS DE HOMENS VIÚVOS DIANTE DA EXPERIÊNCIA DE LUTO CONJUGAL
}

\author{
NARRATIVES OF WIDOWED MEN IN THE EXPERIENCE OF CONJUGAL \\ MOURNING
}

IVANIA JANN LUNA

Universidade Federal de Santa Catarina, Florianópolis/SC, Brasil
RESUMO: Neste artigo é apresentada uma pesquisa qualitativa que visou à compreensão das narrativas de homens viúvos vivenciando luto conjugal. Foram entrevistados três homens que se encontravam na época da perda em um momento específico do ciclo vital da família. Utilizou-se a entrevista qualitativa em profundidade e na organização dos dados foram utilizados os procedimentos de codificação da Teoria Fundamentada. Foram destacadas três categorias temáticas que constituem as dimensões da experiência de luto conjugal: 'Dizer olá novamente', 'Deixar ir' e 'Seguir em frente'. As narrativas produzidas possibilitaram aos enlutados a reconstrução do seu sistema de significados em duas direções: manter viva a relação que tinham com a esposa e construir novos significados para o self, tendo em vista o papel de progenitor viúvo em um ambiente familiar e social em transformação.

PALAVRAS-CHAVE: Perda; Luto; Viúvos; Narrativa.
ABSTRACT: This article presents a qualitative research that aimed to understand the narratives of widowed men experiencing conjugal mourning. Three men were interviewed who were at the time of loss at a specific time in the family life cycle. We used the qualitative interview in depth and in the organization of the data were used the coding procedures of the Grounded Theory. Thus, three thematic categories that constitute the dimensions of the experience of conjugal mourning stand out like: 'say hello again', 'let go' and 'move on'. The narratives produced allowed the bereaved to reconstruct the system of meanings and took place in two directions: restore self-related meanings before loss, that is, keeping alive the relationship they had with the wife; and to construct new meanings for the self in view of the role that was being announced in the situation of mourning, that of a widowed parent in a changing family and social environment.

KEYWORDS: Loss; Mourning; Widows; Narrative.

\section{INTRODUÇÃo}

Uma situação de luto coloca-se à medida que a pessoa, família e/ou comunidade se defrontam com a morte e/ou separação de um ente querido ou algo significativo. Especificamente, na língua inglesa, observam-se terminologias para diferenciar a situação de luto (bereavement), a experiência subjetiva de sofrimento (grief) e o seu compartilhamento social (mourning). A importância da distinção das terminologias tem sido apontada por Walter $(1996,2007)$ quando discute a secularização da morte e da situação de luto nas sociedades britânica e inglesa, e a consequente delimitação de um campo de conhecimento - Psicologia do Luto - envolvido na compreensão da experiência subjetiva de sofrimento e o seu compartilhamento social. Na literatura brasileira, observa-se que Franco (2002, 2010), pesquisadora brasileira e tradutora dos livros de Colin Parkes Aprovado em: 05/06/2019 
complicações (2009) -, traduziu bereavement como luto, grief como pesar e experiência de luto e mourning como enlutamento, sendo que neste artigo serão utilizados preferencialmente os termos experiência de luto e enlutamento. Proceder-se-á, desse modo, à revisão de perspectivas epistemológicas sobre a experiência de luto a fim de apontar o posicionamento que serviu de base para a pesquisa realizada com homens viúvos.

O desafio dos pesquisadores e clínicos, no início e metade do século XX, se deu no sentido de afirmar que a experiência de luto trata de um fenômeno psicológico distinto de outros estados emocionais. Assim, Freud (1917/1974), Lindemann (1944), Bowlby (1961) e Parkes (1988), ao privilegiarem uma visão universal de homem, sobretudo aliada a uma perspectiva epistemológica positivista, deram ênfase à visão de que vivenciar uma perda, do ponto de vista psicológico, implica um modelo normativo de adaptação e resolução de perda, que sustenta a compreensão do que seja a experiência de luto normal ou patológica.

Por sua vez, o padrão normativo indica que a pessoa enlutada realiza operações intrapsíquicas e interpessoais em direção ao esvaziamento do ego quanto às lembranças em relação à pessoa que morreu para que, posteriormente, ocorra a reintegração da pessoa perdida por meio da manutenção de memórias, de modo que a pessoa que morreu assume psiquicamente o lugar de um ausente no funcionamento psíquico atual. Essa perspectiva denota a importância da externalização do sofrimento por meio da expressão das emoções da perda.

Observa-se que, a partir da década de 1980, emerge outro cenário epistemológico no horizonte das discussões sobre a experiência de luto, ou seja, o construtivismo. Este lança ao campo do conhecimento o desafio de redefinir o modelo de adaptação e resolução de uma perda sob a ótica do significado. E isso implica, segundo Neimeyer (2001), Attig (2001), Nadeau (1998), Bonano, Boerner e Wortann (2008) e Walsh (2005), destacar a competência discursiva e relacional das pessoas enlutadas e suas famílias quanto a reconstruir o seu sistema de significados. Para tanto, o conceito de autoria torna-se um importante aspecto no estudo da experiência de luto na medida em que possibilita compreender o protagonismo e a singularidade desse fenômeno.

Em consonância com a discussão construtivista encontra-se o posicionamento construcionista social sobre a experiência de luto, e que inspira o campo do conhecimento quanto à importância de se desconstruir o discurso sobre a experiência de luto que predominou ao longo do século $\mathrm{XX}$, chamado de universalização e uniformização do enfrentamento da perda (Walter, 1997, 2006). Neste contexto discursivo, a experiência de luto do homem viúvo pode não ser compreendida, uma vez que predomina na sociedade ocidental um modelo de externalização do sofrimento que dá foco à expressão das emoções da perda. O seguinte trocadilho citado por Stelle e Uchida (2004, p.85) ilustra esta questão: "mulheres enlutam e homens substituem".

Zinner (2000), por sua vez, demonstra que há outro modo de externalização do sofrimento denominado pela autora como estilo de enlutamento masculino cuja principal característica consiste na expressão de emoções de maneira privada, ou ainda com pessoas muito específicas da sua rede de relacionamentos, por meio de ações que visam antes à obtenção de companhia do que demonstrar a necessidade 
de apoio emocional para o sofrimento. Nesse sentido, os resultados das pesquisas de Wortman e Silvermann (1989) corroboram a visão de que nem sempre os enlutados vivem a experiência de luto por meio da reorganização do comportamento, revisão da identidade e o fim da relação com a pessoa que morreu.

No âmbito da terapia familiar encontra-se o trabalho de Michael White (2004), terapeuta internacionalmente conhecido, que propõe práticas de despatologização do luto. Este autor questiona o rótulo 'luto patológico' que é dado aos enlutados, por profissionais de saúde ou sua comunidade, devido às constantes lembranças que estes têm dos entes queridos, como também pela incapacidade de seguir a vida sem a pessoa que morreu.

Por meio do seu trabalho clínico Michael White demonstrou que os enlutados necessitavam se reconectar aos seus entes queridos, por isso, desenvolveu um trocadilho no qual explicita o seu questionamento. Ao invés de sugerir dizer 'adeus' a alguém que se ama, indicou aos enlutados dizerem 'olá novamente'. Desta forma, apresentou uma proposta conversacional chamada 'clube da vida', por meio da qual estimulava os enlutados a gerar testemunhos sobre os aspectos que contribuíram para a construção do self e da vida relacional da pessoa antes da perda. Por sua vez, dizer 'olá novamente' é denominado por Klass, Silvermann e Nickmann (1996) por meio do termo 'vínculos contínuos', que significam a restauração de atos simbólicos em torno das lembranças, legados, percepções, imagens e significados relacionados à pessoa que morreu.

Verificou-se, de acordo com Lago-Falcão (2009) e Oliveira e Lopez (2008), que nos estudos brasileiros sobre a experiência de luto conjugal há a predominância da participação de mulheres viúvas. Segundo esses autores, a experiência da perda do par conjugal é ainda mais frequente entre as mulheres devido à sua maior expectativa de vida. Os estudos brasileiros cujo foco é a viuvez masculina estão centrados na idade adulta tardia, e apontam para os riscos quanto à saúde mental de viúvos idosos em termos de depressão e comportamento suicida.

Tendo em vista os aspectos abordados acima e inspirando-se nos posicionamentos construcionista social e construtivista, que nos dizem sobre a importância de se trabalhar com aportes teóricos que conceituam a experiência de luto como competência discursiva e relacional na reconstrução do sistema de significados, foi realizada uma pesquisa qualitativa com objetivo de compreender as narrativas de homens viúvos e que sustentam a experiência de luto conjugal. Para tanto, este artigo apresenta as narrativas de três homens enlutados após um ano e seis meses ou até no máximo seis anos e três meses da ocorrência da perda da esposa. Além disso, discute-se a autoria dos participantes na reconstrução do seu sistema de significados a partir das narrativas produzidas.

Este artigo visa ao oferecimento de subsídios para amigos, familiares, vizinhos, colegas de trabalho ou estudo, bem como profissionais de qualquer área do conhecimento compreenderem e desenvolverem relações de apoio psicossocial diante de pessoas enlutadas considerando a perspectiva teórica assumida neste trabalho: o protagonismo de homens viúvos frente à experiência de luto conjugal. Neste sentido, pretende-se contribuir com a desconstrução do discurso dominante sobre a experiência de luto - a universalização e uniformização do enfrentamento da perda. 


\section{MÉTODO}

O desafio de compreender as narrativas que sustentam a experiência de luto como um processo sistêmico e construído na linguagem instaura a problemática da responsabilidade relacional diante da produção do conhecimento, o que implica, segundo McNamee (2010), que decisões metodológicas sejam, sobretudo, práticas para estar em relação com o outro (os participantes da pesquisa). Nesse sentido, a escolha pela pesquisa qualitativa possibilitou gerar dados que se referem aos significados compartilhados pelo pesquisador e pesquisados em torno de uma problemática que interessa a ambos (McNamee, 2010). Além disso, são dados que estão irremediavelmente interligados às relações mantidas entre estes dois atores num determinado momento do tempo.

Propõe-se, desta forma, uma pesquisa que busca a produção do conhecimento contextualizado, relacional e singular. Para tanto, privilegiou-se um delineamento de pesquisa de cunho exploratório e descritivo, que possibilitou a construção de relações horizontais, e de uma postura colaborativa e de respeito frente às vivências e significados advindos de uma perda. A indicação, a seleção e a abordagem de homens enlutados foram intermediadas pelo apoio da rede profissional da pesquisadora. Isso significou que colegas de profissão consultaram previamente homens enlutados quanto ao interesse deles em participar de uma pesquisa sobre a experiência de luto. A partir dessa primeira abordagem foi possível conversar diretamente com os homens que foram indicados pela rede profissional. Os critérios de inclusão estabelecidos foram dois: ter vivido a perda da esposa em um momento do ciclo de vida familiar, como a fase de paternidade, filhos adolescentes ou família no meio da vida (Cerveny \& Berthoud, 2002) e o tempo transcorrido desde a perda ser superior a 6 meses. Desta forma, três homens enlutados foram intencionalmente escolhidos, sendo que cada um se encontrava numa etapa diferente do ciclo vital da família na época da perda.

Esta pesquisa pautou-se no cuidado ético à pessoa enlutada, que indica que não é recomendada a abordagem direta sem que tenha ocorrido previamente uma consulta sobre o interesse em participar de uma pesquisa científica (Franco, Tinoco. \& Mazzora, 2017). Além disso, foram observados os cuidados recomendados pela Resolução no 466/2012 do Conselho Nacional de Saúde, que indica como primordial a emissão do parecer de aprovação da comissão de ética, cujo número é 2.083.286.

O processo de coleta de dados implicou a realização de uma entrevista qualitativa em profundidade com os participantes no local de sua escolha. $\mathrm{Na}$ realização das três entrevistas a postura da pesquisadora foi colaborativa, e isso significou um olhar recursivo tanto para as cinco temáticas presentes em um roteiro previamente delimitado (vínculos afetivos, a circunstância da morte, as emoções da perda, as mudanças e os relacionamentos de apoio) quanto para as condições físicas, emocionais e relacionais dos participantes na produção de suas narrativas singulares.

A primeira entrevista foi realizada com o participante G. e ocorreu em março de 2017, após seis anos e três meses da perda da esposa I., ocorrida em dezembro de 2011. A duração do tratamento para a leucemia de I. foi em torno de dois anos. Já o participante S. foi o segundo entrevistado, em abril de 2017, após um ano e seis meses 
da morte da esposa M., ocorrida em outubro de 2015. A duração do tratamento para o câncer no intestino de M., que estava em estágio avançado quando foi diagnosticado, foi de três meses. A última entrevista realizada foi com o participante $\mathrm{H}$., que ocorreu em maio de 2017, após três anos e um mês da morte da esposa B., ocorrida em abril de 2014. A duração do tratamento para o câncer de pulmão de B., que estava em estágio avançado quando foi diagnosticado, foi de três meses.

As entrevistas foram gravadas e transcritas para que as ferramentas analíticas principais - as perguntas e comparações - possibilitassem conduzir uma análise conceitual qualitativa, por meio de procedimentos típicos de codificação, como a aberta, a seletiva e a axial da Teoria Fundamentada, de acordo com Strauss e Corbin (2008). Deste modo, o processo de codificação aberta se referiu aos elementos temáticos que se destacaram a partir da análise minuciosa de cada frase contida na transcrição da entrevista. Após esta etapa ocorreu a codificação seletiva, que se referiu à seleção dos temas semelhantes e diferentes e a posterior definição de pontos nucleares (subcategorias) que constituem as principais narrativas de cada entrevista. Desta forma, chegou-se ao processo de codificação axial, que consistiu em agregar um conjunto de narrativas em torno de um núcleo comum de significados, de modo que nesta etapa emergiram as categorias temáticas/dimensões da experiência de luto.

Neste processo de organização e integração dos dados obtiveram-se três categorias e suas respectivas subcategorias: Dizer olá novamente (dinâmica das relações familiares no ciclo vital; papel do homem diante do cuidado ofertado à esposa; rede de apoio durante o tratamento de saúde da esposa); Deixar ir (vivências emocionais de luto; despedidas personalizadas nos rituais de luto; e relações de apoios na situação de luto); Seguir em frente (questionamento das dificuldades na retomada da vida familiar e pessoal; relações de apoio diante das dificuldades práticas e emocionais; e ritual de redefinição da identidade pessoal). $\mathrm{Na}$ sequência são apresentados os participantes e as narrativas que sustentam a experiência de luto, bem como se faz a discussão dos principais resultados.

\section{RESULTADOS E DISCUSSÃO}

Inicia-se a apresentação dos resultados com a caracterização dos participantes da pesquisa, da esposa que faleceu e do momento da perda no ciclo vital da família. O participante G. é um empresário no ramo alimentício, tem 54 anos e estava morando com seu filho de 10 anos no momento em que ocorreu a entrevista. A sua esposa I. tinha graduação em Psicologia e Administração e era mestre em Administração. No período que antecedeu ao seu adoecimento, era psicóloga de um órgão público e realizava trabalhos proeminentes com saúde do trabalhador. O tempo de relacionamento conjugal foi de 23 anos. Na época da perda o casal morava com o filho de quatro anos. $\mathrm{O}$ participante S. é pastor, tem 42 anos e atualmente mora com uma filha de 21 anos, um filho de 19 anos e outra filha de 15 anos. A esposa M. também era pastora. O tempo de relacionamento conjugal foi de 20 anos. Na época da perda o casal morava com os três filhos adolescentes. $\mathrm{O}$ participante $\mathrm{H}$. tem 67 anos, é oficial do exército aposentado e atualmente mora sozinho. A esposa B. ocupava um cargo de chefia em uma instituição pública de seguridade social, e pelo tempo de serviço e contribuição já poderia ter se aposen- 
tado, mas gostava do trabalho que fazia e por isso estava postergando essa decisão. $\mathrm{O}$ tempo de relacionamento conjugal foi de 39 anos e gerou dois filhos. Na época da perda somente o filho mais velho morava com o casal.

Conforme já exposto no método, a organização da análise qualitativa dos dados gerou três categorias e nove subcategorias, de modo que nos quadros 1, 2 e 3 são apresentados exemplos de narrativas de todos os participantes em pelo menos uma subcategoria de cada categoria. É importante destacar que não foi possível expor todas as narrativas que representam cada subcategoria, tendo em vista a extensão delas e o limite de páginas deste artigo. Além disso, buscou-se manter uma padronização na ordem de apresenta- ção das narrativas considerando a categoria e subcategoria que está sendo exposta, ainda que cada participante tenha relatado de forma singular a sua experiência de luto durante o processo de entrevista. Inicia-se a discussão dos dados pela apresentação da primeira categoria e na sequência é apresentada a segunda e depois a terceira categoria.

\section{Categoria 1 - Dizer olá novamente}

De acordo com o quadro 1, a primeira categoria temática está composta por subcategorias/narrativas que aludem às relações familiares no ciclo vital da família e às relações de apoio tendo em vista o cuidado que foi ofertado à esposa doente.

\section{Quadro 1 - Subcategorias e narrativas em torno do Dizer olá novamente}

\section{Subcategorias}

\begin{tabular}{l|l}
\multicolumn{2}{l}{ Subcategorias } \\
\hline $\begin{array}{l}1.1 \text { Dinâmica } \\
\text { das relações } \\
\text { familiares no } \\
\text { ciclo vital }\end{array}$ & $\begin{array}{l}\text { Não é porque era a minha esposa; é porque ela era uma pessoa } \\
\text { excepcional em todos os sentidos, né. Boa companheira; } \\
\text { boa amante; boa mãe; boa amiga (...) Justamente porque a } \\
\text { gente estava num momento tão bom da nossa vida: os dois } \\
\text { maduros, os dois sabendo o que queriam. Sabendo viver, } \\
\text { assim... e veio essa doença... O relacionamento estava bom. } \\
\text { Os filhos já tinham saído [de casa], né! (Participante H.) }\end{array}$ \\
\hline $\begin{array}{l}1.2 \text { Papel do } \\
\text { homem dian- } \\
\text { te do cuidado } \\
\text { ofertado à es- } \\
\text { posa }\end{array}$ & $\begin{array}{l}\text { Nós estávamos juntos, recebemos o comunicado juntos (...). } \\
\text { eu disse: - olha, não é assim, a gente conheceu pessoas que } \\
\text { também conseguiram reverter'! (...) mas o que nos moveu } \\
\text { de continuar insistindo e apostando mesmo no cuidado dela } \\
\text {.. era uma luta mesmo assim né de querer até que o último } \\
\text { instante pudesse ter uma reviravolta. (Participante S.) }\end{array}$ \\
\hline $\begin{array}{l}1.3 \text { Rede de } \\
\text { apoio durante } \\
\text { o tratamento } \\
\text { de saúde da } \\
\text { esposa }\end{array}$ & $\begin{array}{l}\text { Além da sobrinha tinham os vizinhos que me apoiavam e } \\
\text { teve um grande apoio que foi durante a doença também de } \\
\text { uma equipe de amigos que se formaram em torno dela, que } \\
\text { dormiam com ela no hospital, dormiam uma noite, outras } \\
\text { pessoas dormiam 7, 8 noites com ela, sempre tinha que ter } \\
\text { acompanhantes... Existia uma rede de apoio, para outra coisa } \\
\text { também, além do que ela precisava (...) lá em casa, eu também } \\
\text { precisava de ajuda. (Participante G.) }\end{array}$ \\
\hline
\end{tabular}


A narrativa que se refere à subcategoria dinâmica das relações familiares no ciclo vital (1.1) descreve o relacionamento do participante $\mathrm{H}$. com a esposa antes do adoecimento. De acordo com o seu relato, percebe-se o bom vínculo conjugal e que antes do adoecimento estavam renegociando o sistema conjugal como díade e a mudança da função do casamento (McCullough \& Rutenberg, 1995). Os outros dois participantes também relataram na entrevista que realizavam tarefas relacionadas ao seu ciclo vital familiar: o participante G. e sua esposa desenvolviam uma tarefa central da fase da paternidade, ou seja, a união do casal nas tarefas da educação dos filhos, financeiras e domésticas (Cerveny \& Berthoud); já o participante S. e sua esposa tinham a tarefa de flexibilizar as fronteiras familiares para incluir a independência dos filhos adolescentes (Cerveny \& Berthoud, 2002).

Também se observou nas entrevistas que os participantes descrevem a dinâmica do vínculo conjugal de modo que o papel dos cônjuges quanto à manutenção da integridade da relação conjugal se torna evidente diante do adoecimento. Neste sentido, destaca-se a subcategoria papel do homem diante do cuidado ofertado à esposa (1.2), de acordo com a narrativa do participante S., que se refere ao apoio emocional e prático que foi dado a ela no momento do diagnóstico e durante todo o tratamento. Isso indica, por sua vez, que o protagonismo do homem no contexto do adoecimento foi direcionado às necessidades da esposa e que o cuidado ofertado foi complementado por uma rede de apoio, sendo esta a terceira subcategoria (1.3).

De acordo com o exemplo dado no quadro 1 , o participante G. relata que pôde contar com a rede de relacionamentos composta por amigos, colegas de trabalho e familiares para auxiliá-lo nos cuidados relacionados ao tratamento de saúde da esposa, e outros aspectos que envolviam o cuidado do filho e da casa. Os outros dois participantes também destacaram esta questão, e demonstraram o quanto foi importante contar com a ajuda de amigos e familiares para conduzir a situação de adoecimento e demais rotinas familiares.

Esse resultado é discutido na pesquisa realizada por Lago-Falcão (2009) com viúvos e viúvas. Esta autora demonstra que os homens recebem mais ajuda da rede familiar e de amigos para cuidar da esposa do que a esposa/viúva em situação semelhante. Desta forma, ainda que no estudo desta autora as mulheres tenham sido as principais protagonistas do cuidado que foi ofertado aos esposos doentes, no estudo aqui realizado se vê que os homens não abdicaram do seu papel de protagonistas do cuidado oferecido às esposas, muito menos do cuidado parental dados aos filhos, pelo menos os participantes G. e S., que estavam com filhos com idades em que a responsabilidade parental é dos progenitores.

Finaliza-se a discussão da primeira categoria apontando que as narrativas produzidas pelos participantes aludem ao 'Dizer olá novamente' de Michael White (2004). Isso significa que os participantes retomaram significados relacionados à dinâmica das relações familiares em uma etapa do ciclo vital em que ocorreu a doença e a morte da esposa, bem como o seu papel de apoio e dos demais relacionamentos que serviram de suporte para ações de cuidado ofertadas à esposa. Sendo assim, 'Dizer olá novamente' implicou reafirmar signifi- 
cados que compõem o self dos participantes, de modo que se pode dizer que na experiência de luto conjugal não se percebe o fim do relacionamento com a pessoa que morreu ou com as pessoas que foram significativas em termos do apoio dado num momento de fragilidade da família, mas a restauração dos modos pelos quais haverá uma interação simbólica com estas pessoas, ainda que ocorra na sua ausência física.

$\mathrm{Na}$ sequência apresenta-se o quadro 2, e que se refere a segunda categoria, 'Deixar ir'. Esta temática pôde ser visualizada na entrevista quando os participantes puderam produzir narrativas em torno do 'Dizer olá no- vamente', pois para 'Deixar ir' é necessário que se mantenham intactos significados que se relacionam à importância dos vínculos afetivos, familiares e de amizade na etapa do ciclo vital em que ocorreu a perda.

\section{Categoria 2 - Deixar ir}

De acordo com o quadro 2, a categoria 'Deixar ir' traz no seu bojo um conjunto de subcategorias/narrativas que caracterizam as vivências emocionais, comportamentais e sociais de luto, ou seja, reações geradas pela ameaça de perda ou pela perda já concretizada.

\section{Quadro 2 - Subcategorias/narrativas em torno do Deixar ir}

\section{Subcategorias/narrativas}

\begin{tabular}{|c|c|}
\hline $\begin{array}{l}2.1 \text { Vivências } \\
\text { emocionais de } \\
\text { luto }\end{array}$ & $\begin{array}{l}\text { Ela me ligou do hospital falando assim pra mim: "eu } \\
\text { estou com leucemia, não posso mais sair do hospital, } \\
\text { cuida do meu filho... O que eu tinha na mão eu joguei, } \\
\text { e... aí eu realmente perdi o controle... Fiquei calmo na } \\
\text { hora que recebi a notícia do médico? Não, eu não fiquei } \\
\text { calmo. Mas eu acho que não tive muita reação física, } \\
\text { assim de, eu não perdi a calma, não perdi o controle. } \\
\text { Emocionalmente eu diria pra você que eu nunca fui } \\
\text { de me abrir muito, nem sempre eu me abria na minha } \\
\text { totalidade com muita gente, exceto com um amigo ou } \\
\text { dois e depois ficava com a coisa mais prática, vivendo de } \\
\text { uma forma mais reservada nesse sentido, tipo vou tocar } \\
\text { a vida, vou resolver. (Participante G.) }\end{array}$ \\
\hline $\begin{array}{l}2.2 \text { Despedidas } \\
\text { personalizadas } \\
\text { nos rituais de } \\
\text { luto }\end{array}$ & $\begin{array}{l}\text { Tinham pessoas que diziam que eu não deveria levar meu } \\
\text { filho pra ver ela (mãe), pra participar do velório. E eu } \\
\text { disse "não". Aí eu fui cantando a musiquinha para o V. } \\
\text { (filho) e para ela. "mãezinha do céu, não sei rezar, só sei } \\
\text { dizer quero te amar". (Participante G.) }\end{array}$ \\
\hline $\begin{array}{l}2.3 \text { Relações } \\
\text { de apoios na } \\
\text { situação de luto }\end{array}$ & $\begin{array}{l}\text { Ela faleceu na segunda ao meio dia e eu fiquei até domingo } \\
\text { à noitinha... então essa amiga telefonou dizendo que ela } \\
\text { tinha acabado de falecer...foi bem importante que ele } \\
\text { (pai) esteve ali também... ele tava ali também no dia da } \\
\text { morte né, mas como companhia. (Participante S.) }\end{array}$ \\
\hline
\end{tabular}

Nova Perspectiva Sistêmica, n. 64, p. 032-046, agosto 2019. 
Visualiza-se no quadro acima que a primeira subcategoria, vivências emocionais de luto (2.1), está composta pela narrativa do participante G., que relatou os intensos sentimentos de revolta e choque, principalmente no momento do diagnóstico, sendo este aspecto corroborado pelas narrativas dos outros dois entrevistados no contexto da entrevista. Zinner (2008) discute que os homens apresentam raiva, irritabilidade e impaciência como emoções típicas de perda, por outro lado, salienta que eles precisam manter um controle ativo sobre seus sentimentos e obrigações. Esta autora também sinaliza que os homens enlutados usam o humor e modos indiretos para expressar suas emoções, bem como são ativos na busca por significados que nomeiam o seu processo de luto.

Para tanto, observa-se que a segunda subcategoria se refere às despedidas personalizadas nos rituais de luto (2.2). Na narrativa do participante G. se observa que este fez um gesto simbólico de despedida junto com o filho, demonstrando, assim, a importância do vínculo conjugal e materno-filial. Já o participante $\mathrm{H}$. relatou na entrevista que fez um gesto de despedida, o que implicou simbolicamente se reunir à esposa falecida no momento em que ela estava sendo enterrada. $\mathrm{O}$ participante $S$. relatou que ele e seus filhos permaneceram duas semanas na cidade natal da esposa e local onde ela foi enterrada com o objetivo de se reconectar aos principais valores da mãe e que seriam seguidos dali para frente. Casellato (2015) aponta que nos rituais de despedidas personalizados corre-se o risco de a sociedade não legitimar o modo como cada pessoa realiza as homenagens, assim, pode-se gerar uma reação de não reconhecimento social das pessoas quanto ao direito de se enlutar de modo muito específico.
Por sua vez, no quadro 2, observa-se a subcategoria que assinala a importância das relações de apoio na situação de luto (2.3). No relato do participante S., o apoio dado por familiares e amigos diante da morte da esposa foi muito significativo, o que foi corroborado pelos outros dois participantes durante a entrevista. Zinner (2000) aponta que as emoções da perda são expressas pelo homem em locais seguros e que eles buscam mais companhia social do que suporte emocional no seu processo de luto.

Finaliza-se a discussão da segunda categoria destacando que as narrativas produzidas sinalizaram a internalização das emoções da perda, e isso significou mantê-las sob o domínio privado e controlado. Além disso, aponta-se que há narrativas em torno da externalização das emoções, a partir das homenagens personalizadas nos rituais de luto, bem como as relações de apoio preferidas e que deram suporte à expressão das emoções da perda. Neste sentido, a categoria 'Deixar ir' implicou a produção de narrativas que sinalizam o momento de transição em que se encontravam diante da realidade da morte da esposa. Sendo assim, são narrativas que se relacionam aos significados quanto a se conduzir num ambiente familiar e social em transformação. Na sequência apresenta-se o quadro 3, que se refere à terceira categoria temática.

\section{Categoria 3 - Seguir em frente}

A categoria 'Seguir em frente' traz no seu bojo um conjunto de subcategorias/narrativas que caracterizam as mudanças no ambiente familiar e social e a transição de papéis, como pode ser observado no quadro 3 . 
Subcategorias/narrativas

\begin{tabular}{l|l}
\hline $\begin{array}{l}\text { Questiona- } \\
\text { mentos e difi- } \\
\text { culdades na re- } \\
\text { tomada da vida } \\
\text { familiar e pessoal }\end{array}$ & $\begin{array}{l}\text { Questões de casa, com cuidado que eram necessárias e, } \\
\text { de cuidar da limpeza, de cuidar da comida, da roupa, o } \\
\text { cuidado com a casa, com o lar em si né, o chamado "lar" } \\
\text { néficuldade prática e isso também tem uma carga } \\
\text { emocional porque também tem você não saber fazer } \\
\text { direito e nunca fez, e agora precisa fazer, e você não sabe } \\
\text { direito fazer... o casamento desapareceu ... aí surge muitas } \\
\text { dúvidas: 'aonde me coloco? como me comporto agora? o } \\
\text { que eu quero?" Definir o que eu quero... (Participante G.) }\end{array}$ \\
\hline $\begin{array}{l}\text { 3.2 Relações de } \\
\text { apoio diante } \\
\text { das dificuldades } \\
\text { práticas } \\
\text { emocionais }\end{array}$ & $\begin{array}{l}\text { Então a primeira semana ficou uma irmã aqui comigo, } \\
\text { ela até quis ficar mais mas eu disse "quer ficar, fica, mas } \\
\text { eu vou ter que me acostumar, mais cedo ou mais tarde } \\
\text { (...) tem que readaptar minha vida, como se eu fosse um } \\
\text { adolescente... tem que começar a se virar sozinho... E } \\
\text { quando eu ia lá (casa da irmã) eu saía com um monte de } \\
\text { potinho de coisa, né. "Ah, leva isso, leva um feijãozinho, } \\
\text { uma carne, não sei o que... Comecei a fazer as coisas } \\
\text { também, a lavar, passar, cozinhar. (Participante H.) }\end{array}$ \\
\hline $\begin{array}{l}\text { 3.3 Ritual de } \\
\text { redefinição da } \\
\text { identidade pes- } \\
\text { soal }\end{array}$ & $\begin{array}{l}\text { Fiz um ano de luto e continuei usando a aliança né, então } \\
\text { quando fez um ano na frente dos meus filhos eu tirei a } \\
\text { aliança e disse: "ó vou tirar a aliança não com prazer, } \\
\text { mas a vida continua e eu tenho que continuar a minha } \\
\text { vida né.... Eu sempre pensava que ia ser assim. Que eu } \\
\text { ia... mas pensava em ficar velhinho, né. E ela também. Ela } \\
\text { empurrando a minha cadeira. Quando eu morresse: Não } \\
\text { esquece de me visitar aqui, é pertinho'. Agora eu estou } \\
\text { fazendo, também. Passo lá toda hora (cemitério). Eu ia } \\
\text { cobrar dela, né, e agora eu estou fazendo. (Participante H.) }\end{array}$ \\
\hline
\end{tabular}

A subcategoria 3.1 se refere aos questionamentos das dificuldades na retomada da vida familiar. De acordo com a narrativa do participante G., observa-se não somente questionamentos em torno da rotina familiar e identidade pessoal, mas também as dificuldades percebidas diante das mudanças ocorridas na família após a morte da esposa, como a transição de papéis, ou seja, de progenitor casado para progenitor viúvo; os outros dois entrevistados também apresentaram narrativas semelhantes. Observa-se, desta forma, que o 'Seguir em frente' envolve o que assinalam Stroebe e Schut (1999) quando discutem que a tendência de homens e mulheres em situação de viuvez é buscar a retomada da rotina, tendo em vista que o papel de progenitor viúvo o coloca na posição de ser o condutor da rotina familiar. Por sua vez, os questionamentos quanto à retomada da vida pessoal também significaram que os participantes conseguiram visibilizar as di- 
ficuldades emocionais em relação à mudança do status conjugal.

Tendo em vista esse aspecto, destacam-se as narrativas sobre as relações de apoio que deram suporte ao enfrentamento tanto das dificuldades práticas quanto das emocionais, sendo esta a subcategoria 3.2. O participante $\mathrm{H}$. relatou ter recebido ajuda prática da irmã nos primeiros dias após a morte da esposa. Por sua vez, os participantes G. e S. relataram na entrevista terem recebido apoio da rede de relacionamentos com relação à reorganização da rotina, através de conselhos e ajuda prática no dia a dia. Além disso, descreveram a ajuda recebida de profissionais psicólogos quanto às dificuldades emocionais, o que os auxiliou a tomar decisões sobre a vida pessoal e familiar. Este aspecto é apontado por Zinner (2000), que destaca que as emoções da perda são expressas pelo homem em locais seguros, longe dos olhos dos outros.

A última subcategoria, ritual de redefinição da identidade pessoal (3.3), designa o modo como os participantes lidaram com a retomada da sua identidade no contexto das relações familiares e sociais. Observa-se na narrativa do participante $\mathrm{H}$. a comunicação da decisão aos filhos de que iria tirar a aliança e que seguiria a sua vida afetiva por meio de um possível relacionamento afetivo, além disso, traz a ideia de continuidade do vínculo com a esposa mediante as suas visitas constantes ao cemitério. A continuidade do vínculo afetivo também pode ser observada na entrevista com o participante G., que relatou a publicação de um livro autobiográfico sobre a vida da esposa (Tavella, 2018) (foi escrito por um jornalista em primeira pessoa tendo como referência o diário da esposa de G.) com o objetivo de que a história de vida dela seja uma história viva para o filho, ou seja, que esta o acompanhe ao longo das diversas fases do seu desenvolvimento. Desta forma, o participante G. redefine simbolicamente o seu novo papel na família, ou seja, de viúvo solteiro e de ser aquele quem sutura a ameaça que a perda da mãe/esposa trouxe à continuidade do ciclo de vida familiar (paternidade com filhos pequenos). De forma semelhante, o participante S. relata que a redefinição da sua identidade pessoal se deu quando anunciou às pessoas do seu trabalho e à sua família o foco da sua atenção, ou seja, a educação e cuidado dos filhos. Para Shapiro (1994), na experiência de luto conjugal está presente a questão da retomada da identidade familiar, e isso significa a restauração do fluxo desenvolvimental da família, ou seja, a continuidade do self familiar, mas também do self individual. E isso pode implicar assumir outros relacionamentos, integrá-los à dinâmica familiar recentemente reconstituída, ou ainda dar outros rumos à vida familiar e pessoal.

Finaliza-se a discussão da terceira categoria destacando que as narrativas produzidas em torno do 'Seguir em frente' possibilitaram a construção de novos significados e compõem o self dos participantes em um ambiente familiar e social em transformação. Por sua vez, esta categoria interliga-se a primeira e a segunda ('Dizer olá novamente' e 'Deixar ir') na medida em que a transição de papéis, ou seja, de progenitor casado para progenitor viúvo, envolve paralelamente o esforço de resgatar os significados sobre o vínculo afetivo que os participantes tinham com a esposa e as vivências emocionais deflagradas pela doença e a morte dela. Para tanto, as três categorias são importantes norteadores para se compreender a experiência de luto conjugal de homens viúvos; destaca-se 
também que cada uma delas é uma das dimensões dessa experiência.

\section{CONSIDERAÇ̃̃ES FINAIS}

O estudo realizado visou à compreensão da experiência de luto de homens viúvos que se encontravam em um momento específico do ciclo vital da família quando ocorreu a perda da esposa devido ao adoecimento por câncer, como na fase da paternidade, na fase com filhos adolescentes e na idade tardia. Verificou-se que as narrativas produzidas pelos participantes destacam três dimensões da experiência de luto: 'Dizer olá novamente', 'Deixar ir e 'Seguir em frente'. Observou-se que a diferença de tempo transcorrido desde a perda, tendo em vista o momento em que ocorreu a entrevista, bem como a etapa do ciclo vital da família em que cada participante se encontrava na época da perda, não trouxe diferenças significativas quanto à produção das diferentes narrativas que sustentam a experiência de luto conjugal e que foram discutidas neste artigo.

As narrativas produzidas implicaram a autoria dos enlutados quanto à reconstrução do sistema de significados que se deu em duas direções: restaurar significados relacionados ao self antes da perda, ou seja, mantendo viva a relação que tinham com a esposa e as relações de apoio tendo em vista o cuidado que foi ofertado à esposa; e construir novos significados para o self, e que dizem respeito a um novo papel social que estava sendo anunciado na situação de luto, o de progenitor viúvo em um ambiente em transformação. Para tanto, o protagonismo dos participantes esteve ancorado no resgate constante das experiências anteriores à perda da esposa, bem como na compreensão das experiências vividas após a morte dela, a partir de novos significados que foram criados para si e para sua família.

Observou-se que as narrativas em torno do 'Dizer olá novamente' permitiram aos participantes reafirmarem a importância do vínculo conjugal e da rede de relacionamentos que os auxiliou a manter a integridade desse vínculo. Essa rede, por sua vez, tornou-se um importante elemento norteador das vivências dos participantes, uma vez que celebra e reafirma as memórias antes e após a perda. Nesse sentido, destaca-se o seguinte questionamento: se a perda tivesse sido repentina, quais seriam as narrativas de viúvos diante da experiência de luto conjugal? Assim, sugere-se a realização de estudos com homens viúvos, em circunstância de perda repentina da esposa, para compreender quais as narrativas que sustentam a experiência de luto conjugal.

$\mathrm{O}$ estudo apresentado neste artigo possibilita pensar as relações de apoio psicossocial ao homem devido à circunstância de perda antecipada por uma doença grave, tendo em vista as dimensões apresentadas sobre a experiência de luto conjugal. Para tanto, serão retomados alguns resultados do estudo realizado. Quanto à dimensão 'Dizer olá novamente', é importante que o apoio psicossocial promova diálogos e escuta para fortalecer narrativas em torno de qual foi o papel do homem no cuidado ofertado à esposa, o que reforça as memórias sobre o vínculo que se tinha com ela. Essas narrativas estão ligadas ao self antes da perda e, ao serem mantidas, possibilitam narrativas em torno do 'Deixar ir'.

Esta segunda dimensão da experiência de luto aponta que os participantes externalizaram nos rituais de luto as suas emoções de perda a partir 
de um gesto simbólico. Isso significa que o apoio psicossocial nos rituais envolve acompanhar as homenagens que os enlutados fazem aos entes queridos e validar o momento de mudança e transição de papéis. Além disso, após os rituais de luto, o apoio psicossocial pode significar validar as vozes silenciosas dos homens, devido à internalização das emoções de perda, e isso implica reconhecer que há modos diferentes em viver o sofrimento advindo de uma perda. Considera-se que este tipo de apoio é importante tendo em vista uma sociedade que rotula as pessoas que não se encaixam nos modelos normativos de enlutamento.

Outra dimensão da experiência de luto 'Seguir em frente' aponta a questão de se promover diálogos e escuta quanto aos questionamentos que os homens fazem quando estão diante da transição de papéis. Isso implica a possibilidade de eles identificarem as dificuldades e os rituais de redefinição da identidade familiar e pessoal, sendo que narrativas os remetem à possibilidade de construção de novos significados para o self.

Conclui-se este estudo destacando que a experiência de luto conjugal de homens é um processo eminentemente autoral de reconstrução do sistema de significados, e que significa a competência discursiva e relacional da pessoa enlutada quanto a narrar as suas experiências a partir de relatos singulares. Já o apoio psicossocial é uma tarefa que implica oferecer relações de apoio para que a reconstrução do sistema de significados ocorra junto a pessoas de confiança do enlutado e com as quais ele encontra respaldo quando compartilha as suas necessidades e significados. Por isso a importância de relações de apoio com amigos, familiares, vizinhos, colegas de trabalho ou estudo, bem como com profissionais de qualquer área do conhecimento, pois estes são importantes mediadores das vivências de luto. Nesse sentido, é fundamental que se observe a construção de relações de apoio psicossocial que promovam a escuta e a validação de narrativas singulares e que se referem tanto às vivências de ruptura do vínculo afetivo e de uma etapa do ciclo de vida familiar quanto às vivências de continuidade deste ciclo e do vínculo afetivo.

\section{REFERÊNCIAS}

Attig, T. (2001). Relearning the world: making and finding meanings. In R. A. Neimeyer (Ed.), Meaning reconstruction and the experience of loss (pp. 33- 53). Washington: American Psychological Association.

Bonano, G. A. Boerner, K., \& Wortamn, C. B. (2008). Trajetories of grieving. InM. Stroebe, R. Hansson, H. Schut., \& W. Stroebe (Eds.),Handbook of bereavement research and practice advanced in theory and intervention (pp. 287-308). Washington: American Psychological Association.

Bowlby, J. (1961). Processes of mourning. The International Journal of Psycho-analysis,13(4/5), 317-340. Recuperado de https://www.ncbi. nlm.nih.gov/pubmed/13872076

Casellato, G. (2015). Luto não reconhecido: o fracasso da empatia nos tempos modernos. In $O$ resgate $d a$ empatia: suporte psicológico ao luto não reconhecido (pp. 15-28).São Paulo:Summus.

Cerveny, C. M. O. \& Berthoud, C. M. E. (2002). Visitando a família ao longo do ciclo vital. São Paulo: Casa do Psicólogo.

Franco, M. H. Pu (2002). Uma mudança de paradigma sobre o enfoque da morte do luto na contempora- 
neidade. InEstudos avançados sobre o luto (pp. 15-38). São Paulo: Livro Pleno.

Franco, M. H. Pr (2010). Porque estudar o luto na atualidade? InFormação e rompimento de vínculos: o dilema das perdas na atualidade (pp.17-42). São Paulo: Summus.

Franco, M. H. Pu, Tinoco, V. E, \& Mazorra, L. (2017). Reflexões sobre os cuidados éticos na pesquisa com enlutados. Revista M. Rio de Janeiro, 2(3), 138-151.

Freud, S. (1974). Luto e melancolia. In Edição Standard Brasileira das obras psicológicas completas de Sigmund Freud (J. Salomão, trad., vol.14, pp. 271-291). Rio de Janeiro, RJ: Imago. (Original publicado em 1917)

Grandesso, M. (2008). Dizendo olá novamente: A presença de Michael White entre nós terapeutas familiares. Revista Brasileira de Terapia Familiar, 1(1), 65-78.

Klass, D., Silvermann, S., \& Nickmann, S. (1996). Continuing bonds: new understandings of grief. Washington: Taylor and Francis.

Lago-Falcão, T. M. (2009).Homem não chora: um estudo sobre viuvez masculina em camadas médias urbanas. Tese de Doutorado, Programa de Pós-Graduação em Antropologia, Universidade Federal de Pernambuco, Recife.

Lindemann, E. (1944). Symptomatology and management of acute grief. The American Journal of Psychiatry, 101(2), 141-148.

McNamee, S. (2010). Research as social construction: transformative inquiry. Saúde e Transformação Social, 1(1), 9-19.

McCullough, Ps \& Rutenberg, S. (1995). Lançando os filhos e seguindo em frente. In B. Carter. \& M. MacGoldrick (Eds.), As mudanças no ciclo de vida familiar: uma estrutura para a terapia familiar (2a ed., pp. 248-268). Porto Alegre: Artmed.

Nadeau, J. W. (2008). Meaning-making in bereaved families: assessment, intervention and future research. In M. Stroebe, R. Hansson, H. Schut., \& W. Stroebe (Eds.), Handbook of bereavement research and practice advanced in theory and intervention (pp. 511-530). Washington: American Psychological Association.

Neimeyer, R. A. (2001). Meaning reconstruction and the experience of loss. Washington: American Psychological Association.

Oliveira, J. B. A. \& Lopes, R. G. C. (2008). O processo de luto no idoso pela morte de cônjuge e filho. Psicologia em Estudo, 13(2), 217-221.

Parkes, C. M. (1988). Bereavement as a psychosocial transition: processes of adaptation to change.Journal of Social Issues, 44(3), 53-65. doi/10.1111/j.1540-4560.1988. tb02076.x

Parkes, C. M. (1996). Estudos sobre o luto na vida adulta. São Paulo: Summus.

Parkes, C. M. (2009). Amor e perda: as raízes do luto e suas complicações. São Paulo: Summus.

Resolução n. 466, de 12 de dezembro de 2012. (2012). Define as diretrizes e normas regulamentadoras de pesquisa em seres humanos. Brasília, DF: Presidência da República.

Shapiro, E. (1994). Grief as a family process: a developmental approach to clinical practice.New York: The Guildford Press.

Strauss, A. \& Corbin, J. (2008). Pesquisa Qualitativa: técnicas e procedimentos para o desenvolvimento de teoria fundamentada ( $2^{\text {a }}$ ed.). Porto Alegre: Artes Médicas.

Stelle, C. \& Uchida, M. (2004). The stability and change in the social sup- 
port networks of widowers following spousal bereavement. The Journal of Men's Studies, 13(1), 85-105.

Stroebe, M. \& Schut, H. (1999). The dual process model of coping with bereavement: rationale and description. Death Studies, 23, 197-224. Doi:10.1080/074811899201046.

Tavella, M. (2018). Minha vida em direção ao mar.Florianópolis: Construtores de Memórias.

Walsh, Fu (2005). Fortalecendo a resiliência familiar. São Paulo: Roca.

Walter, T. (1997). A secularização. In C. M. Parkes, P. Laungani, \& B. Young (Orgs.), Morte e luto através das culturas (pp. 195- 220). Lisboa: Climepsi.

Walter, T. (2006). What is complicated grief? A social constructionist answer.Omega, 52(1), 71-79. Recuperado de https://researchportal. bath.ac.uk

White, M. (2004) Decir de nuevo: 'Hola'. InGuia para uma terapia familiar sistêmica(pp.57-68). Barcelona: Gedisa.

Wortman C. \& Silvermann, R. (1989). The myths of coping with loss. Journal of Consulting and Clinical Psychology,57(3), 349-57.

Zinner, E. S, (2000). Being a man about It: the marginalization of men in grief. Illness, Crisis \& Loss, 8(2), 181-188.

\section{AGRADECIMENTOS}

Agradeço aos três homens participantes deste estudo pela oportunidade de escutá-los. Agradeço a Luísa Estácio, Miriã Linhares, Rômulo Delavy e Daniel Maioral pela participação em várias etapas da realização da pesquisa, como na revisão da literatura, na coleta de dados e na organização da análise dos dados.

\section{IVÂNIA JANN LUNA}

É professora do Departamento de Psicologia da Universidade Federal de Santa Catarina. Com formação em Psicologia, Mestrado em Psicologia Clínica (PUC/SP) e Doutorado em Psicologia (UFSC), atua como supervisora de estágios em Psicologia sob enfoque da perspectiva sistêmica e do construcionismo social. É fundadora e coordenadora do Laboratório de Processos Clínicos e Psicossociais no luto (LAPPSILu) da UFSC.

E-mail: ivaniajann@ig.com.br 